\title{
Expression of IL-23R and IL-17 and the pathology and prognosis of urinary bladder carcinoma
}

\author{
JIAN LIU, LEI WANG, TONGQING WANG and JIZHENG WANG \\ Department of Urology, Zhengzhou Central Hospital Affiliated to \\ Zhengzhou University, Zhengzhou, Henan 450000, P.R. China
}

Received October 26, 2017; Accepted July 2, 2018

DOI: $10.3892 / \mathrm{ol} .2018 .9145$

\begin{abstract}
Expression of interleukin-23 receptor (IL-23R) and IL-17 in urinary bladder carcinoma (UBC) was investigated to explore the correlations with prognosis. IL-23/IL-17 axis significantly inhibited the development of inflammatory bowel disease. Thirty patients with UBC were enrolled in Zhengzhou Central Hospital Affiliated to Zhengzhou University from September 2013 to September 2014. Tumor tissue and adjacent healthy tissue were collected, and the levels of IL-23R and IL-17 mRNA were detected by RT-PCR. Thirty healthy people were also selected to serve as normal control group. Serum levels of IL-23R and IL-17 in serum of UBC patients and normal controls were detected by ELISA, and the correlations with clinical features of UBC were analyzed. Pearson's correlation analysis was used to analyze the correlation between IL-23R and IL-17 protein expression. Follow-up study was performed by phone or during patient's visit to out-patient department. Overall survival (OS) and disease-free survival (DFS) curves were plotted by Kaplan-Meier method to analyze the correlation between expression of IL-23R and IL-17 and survival time. ROC curve was used to detect the diagnostic values of IL-23R and IL-17 protein for UBC. Levels of IL-23R and IL-17 mRNA in UBC tissue were 3.26 and 2.65 times higher than those in adjacent tissue $(\mathrm{P}<0.05)$, and serum levels of IL-23R and IL-17 protein in UBC patients were significantly higher than those in normal control group. Protein expression levels of IL-23R and IL-17 were correlated with clinical stage and lymph node metastasis in UBC patients $(\mathrm{P}<0.05)$, and Cox hazard model showed that L-23R and IL-17 expression may be independent factors for UBC $(\mathrm{P}<0.05)$, and high expression levels of IL-23R and IL-17 significantly shortened the OS and DFS $(\mathrm{P}<0.05)$. Serum levels of IL-23R and IL-17 can be used to effectively diagnose clinical stage and lymph node
\end{abstract}

Correspondence to: Dr Jian Liu,Department of Urology,Zhengzhou Central Hospital Affiliated to Zhengzhou University, Ward 1, 195 Tongbai Road, Zhengzhou, Henan 450000, P.R. China

E-mail: jpy62d@163.com

Key words: urinary bladder carcinoma, inflammatory factor, prognosis, IL-17, IL-23R metastasis of UBC patients, and the combined diagnosis has a higher sensitivity and specificity than the diagnosis using a single factor. These findings indicated that expression levels of IL-23R and IL-17 were increased in tumor tissue and serum of UBC patients, and the increased expression levels of IL-23R and IL-17 were correlated with poor prognosis. Detection of IL-23R and IL-17 levels has certain clinical significance in the diagnosis and prognosis of UBC.

\section{Introduction}

Immune cells exist in many types of tissues to protect host cells from inflammatory factors $(1,2)$. It is now clear that the infiltration of various inflammatory factors and disease progression may cause cancer. For example, chronic inflammation caused by Helicobacter pylori and hepatitis virus and other microbial infections may induce the occurrence of gastric and liver cancer $(3,4)$. In addition, non-infectious chronic inflammation is also closely correlated with the development of tumors (5). Inflammation is caused by the secretion of a variety of cytokines by innate immune cells, and the infiltration of cytokines is associated with poor prognosis of cancer patients (6). Some studies suggest that these inflammatory factors may be directly involved in tumor development and metastasis by inducing angiogenesis and tissue remodeling (7).

As a member of the proinflammatory cytokine family receptor, interleukin-23 receptor (IL-23R) is formed by $\mathrm{p} 19$ and p40 subunits. IL-23 can induce the production of Th1 cells and then initiate Th17 cell cascade to produce IL- 6 and TGF- $\beta 1$ and activate memory $\mathrm{T}$ cells (8). IL-23R is highly expressed in tumor tissue to induce local inflammation and promote the development of tumors (9). IL-17 plays a key role in inflammation and autoimmune diseases, including inflammatory bowel disease, multiple sclerosis and rheumatoid arthritis (10). Contradictory findings also exist and some studies found that IL-17 supported tumor growth (11). In contrast, other studies have shown that IL-17 can promote $\mathrm{T}$ cell-mediated tumor rejection (12). Study found that IL-23 could induce IL-17 production by CD4 $\mathrm{T}$ cells (13). In addition, blocking the IL-23/IL-17 axis significantly inhibited the development of inflammatory bowel disease in animal models. These studies suggest that IL-23/IL-17 axis may be a new therapeutic target for the treatment of chronic inflammatory diseases (14). 
Although the roles of IL-23R and IL-17 have been extensively studied in autoimmunity, studies on their roles in cancer, especially urinary bladder carcinoma (UBC), are still relatively insufficient. In this study, levels of IL-23R and IL-17 in tumor tissue of patients with UBC and the effects on the prognosis of patients were investigated. Our study provided theoretical basis for clinical diagnosis and treatment of UBC.

\section{Patients and methods}

Clinical data. In the present study, 30 patients with UBC were included. The patients included 14 females and 16 males, with an average age of 58.3 years. All specimens were diagnosed by pathological examinations. According to the classification criteria established by the World Health Organization (1973), clinical stage of each tumor was determined using histological grading, and there were 5 patients $(16.7 \%)$ in grade I, 9 in grade II (30\%), and 16 in grade III $(53.3 \%)$. Based on radiographic and pathologic findings, TNM staging was performed using the criteria established by American Joint Committee on Cancer (AJCC). Tumor tissues and adjacent healthy tissues were collected during surgical resection. IL-23R and IL-17 mRNA expression level in tumor tissue of 30 UBC patients were detected by RT-PCR. According to the median expression levels of IL-23R and IL-17 mRNA, patients were divided into IL-23R and IL-17 high expression and low expression groups, respectively. Follow-up study was performed for $\sim 30$ months (median length of 23 months) by phone or during patients' visit to out-patient department. After surgery, disease progression was observed in 10 patients, therefore, transurethral surgery was done, and intravesical instillation was performed for 8 weeks. Systemic chemotherapy was performed using methotrexate, cisplatin, doxorubicin and vinblastine. This study was approved by the Ethics Committee of Zhengzhou Central Hospital Affiliated to Zhengzhou University (Zhengzhou, China) and all participants in the study signed an informed consent.

$R T-q P C R$. Total RNA was extracted using RNA extraction kit (Qiagen China Co., Ltd., Shanghai, China) according to the manufacturer's instructions, and $1 \mu \mathrm{g}$ of total RNA was reversely transcribed into cDNA. RT-qPCR was performed using the SYBR ${ }^{\circledR}$ Premix Ex Taq ${ }^{\mathrm{TM}}$ II kit (Takara Biotechnology Co., Ltd., Dalian, China). PCR conditions: $95^{\circ} \mathrm{C}$ for $1 \mathrm{~min}$, followed by 40 cycles of $95^{\circ} \mathrm{C}$ for $10 \mathrm{sec}$ and $55^{\circ} \mathrm{C}$ for $40 \mathrm{sec}$. $\mathrm{Ct}$ values were processed using $2^{-\Delta \mathrm{Ct}}$ method (15). With GAPDH as endogenous control, relative expression level of each gene was calculated using the following formula: $2^{-\Delta \mathrm{Ct}}$ $[\Delta \mathrm{Ct}=\mathrm{Cq}$ (target gene) $-\mathrm{Cq}(\mathrm{GAPDH})]$. Primer sequences are as follows: 5'-CTATGCGGTACTCATATCGCAG-3' (forward) and 5'-GG TTGTATCAATGAATTCC-3' (reverse) for IL-17; 5'-CTTTGAGGAGTTCATATTGTA-3' (forward) and 5'-AA ATTAGCCAGATTGTGGTCT-3' (reverse) for IL-23R; 5'-AT TGATGGATGCTAFGAGTATT-3' (forward) and 5'-AGTCT TCTGGGTGGCA GTGAT-3' (reverse) for GAPDH. This experiment was repeated three times.

ELISA to measure serum levels of IL-23R and IL-17. Whole blood $(25 \mathrm{ml})$ was collected from UBC patients and healthy subjects before operation, and the blood was centrifuged at $1,000 \mathrm{x} \mathrm{g}$ for $1 \mathrm{~h}$ at room temperature to collect serum. Standard sample was diluted with a ratio of 1:50 to draw standard curve. ELISA kit was provided by R\&D Systems, Inc., (Minneapolis, MN, USA). Protein levels of IL-17 (no. P5326; New York, USA) and IL-23R (no. P43432) in serum samples were measured according to the instructions. This experiment was repeated three times to obtain the average value.

Statistical analysis. Results were analyzed using GraphPad Prism software (version 5.01; GraphPad Software, Inc., San Diego, Chile). The data are presented as mean \pm standard deviation. Differences between the two groups were compared using independent sample t-test. Chi-square test was used to analyze the relationship between IL-23R and IL-17 protein levels and clinical parameters of UBC patients. Kaplan-Meier method was used to plot the patient's survival curve and survival curves were compared using log-rank test. The relationship between the expression of IL-23R, IL-17 and the clinical index of UBC was analyzed by COX risk ratio model. Roc curve was used for detecting the diagnostic efficiency of IL-23, IL-17 and combined detection. $\mathrm{P}<0.05$ was considered to indicate a statistically significant difference.

\section{Results}

Expression levels of IL-23R and IL-17 detected by RT-PCR. Expression levels of IL-23R and IL-17 mRNAs in tumor tissues and adjacent tissues of $30 \mathrm{UBC}$ patients were detected by RT-PCR. Results showed that IL-23R and IL-17 mRNA levels in tumor tissues were 3.26 and 2.65 times higher than those in adjacent tissues (Fig. 1), respectively $(\mathrm{P}<0.05)$.

Serum levels of IL-23R and IL-17 detected by ELISA. To further explore the role of IL-23R and IL-17 in UBC, we recruited 30 healthy volunteers as controls. Serum levels of IL-23R and IL-17 protein in patients were detected by ELISA. Levels of IL-23R and IL-17 in serum of UBC patients were significantly higher than those in control group (Fig. 2; $\mathrm{P}<0.05)$.

Relationship between IL-23R and IL-17 expression and clinicopathological features. Chi-square test was used to analyze the relationship between IL-23R and IL-17 protein levels and clinical parameters of UBC patients. As shown in Table I, expression levels of IL-23R and IL-17 were not associated with sex, age, tumor size and pathological grade $(\mathrm{P}>0.05)$, but was significantly associated with clinical stage and lymph node metastasis $(\mathrm{P}<0.05)$.

Cox hazard model analysis. Relationship between IL-23R and IL-17 expression and clinical parameters of UBC patients was analyzed using Cox hazard model analysis. As shown in Table II, sex, age, tumor size and pathological grade were not independent prognostic risk factors for UBC ( $P>0.05)$, so they have no significantly clinical correction with the prognosis of UBC. While clinical stage, lymph node metastasis, the levels of IL-23R and IL-17 were independent prognostic risk factor for UBC $(\mathrm{P}<0.05)$, which were closely related to poor prognosis of patients with UBC. 
Table I. Relationship between IL-23R and IL-17 expression and clinicopathological features of UBC patients using Chi-square test.

\begin{tabular}{|c|c|c|c|c|c|c|c|c|}
\hline \multirow{2}{*}{$\begin{array}{l}\text { Clinicopathological } \\
\text { features }\end{array}$} & \multirow[b]{2}{*}{ No. } & \multicolumn{2}{|c|}{ IL-23R } & \multirow[b]{2}{*}{ P-value } & \multirow[b]{2}{*}{ No. } & \multicolumn{2}{|c|}{ IL-17 } & \multirow[b]{2}{*}{ P-value } \\
\hline & & Low (11) & High (19) & & & Low (10) & High (20) & \\
\hline \multicolumn{9}{|l|}{ Sex } \\
\hline Male & 16 & 5 & 11 & 0.073 & 17 & 6 & 11 & 0.846 \\
\hline Female & 14 & 6 & 8 & & 13 & 4 & 9 & \\
\hline \multicolumn{9}{|l|}{ Age (years) } \\
\hline$\leq 58$ & 15 & 7 & 8 & 0.242 & 11 & 5 & 6 & 0.319 \\
\hline$>58$ & 15 & 4 & 11 & & 19 & 5 & 14 & \\
\hline \multicolumn{9}{|l|}{ Tumor size $(\mathrm{cm})$} \\
\hline$\leq 3$ & 18 & 6 & 12 & 0.054 & 16 & 3 & 13 & 0.544 \\
\hline$>3$ & 12 & 5 & 7 & & 14 & 17 & 7 & \\
\hline \multicolumn{9}{|l|}{ PG } \\
\hline I & 5 & 3 & 2 & 0.054 & 4 & 1 & 3 & 0.075 \\
\hline II & 9 & 6 & 3 & & 10 & 6 & 4 & \\
\hline III & 16 & 2 & 14 & & 16 & 3 & 13 & \\
\hline \multicolumn{9}{|l|}{$\mathrm{CS}$} \\
\hline T0-T1 & 17 & 9 & 8 & 0.034 & 18 & 6 & 12 & 0.043 \\
\hline T2-T4 & 13 & 2 & 11 & & 12 & 4 & 8 & \\
\hline \multicolumn{9}{|l|}{ LM } \\
\hline No & 12 & 6 & 6 & 0.035 & 14 & 4 & 10 & 0.046 \\
\hline Yes & 18 & 5 & 13 & & 16 & 6 & 10 & \\
\hline
\end{tabular}

IL-23R, interleukin-23 receptor; UBC, urinary bladder carcinoma; PG, pathological grade; CS, clinical stage; LM, lymphatic node metastasis.
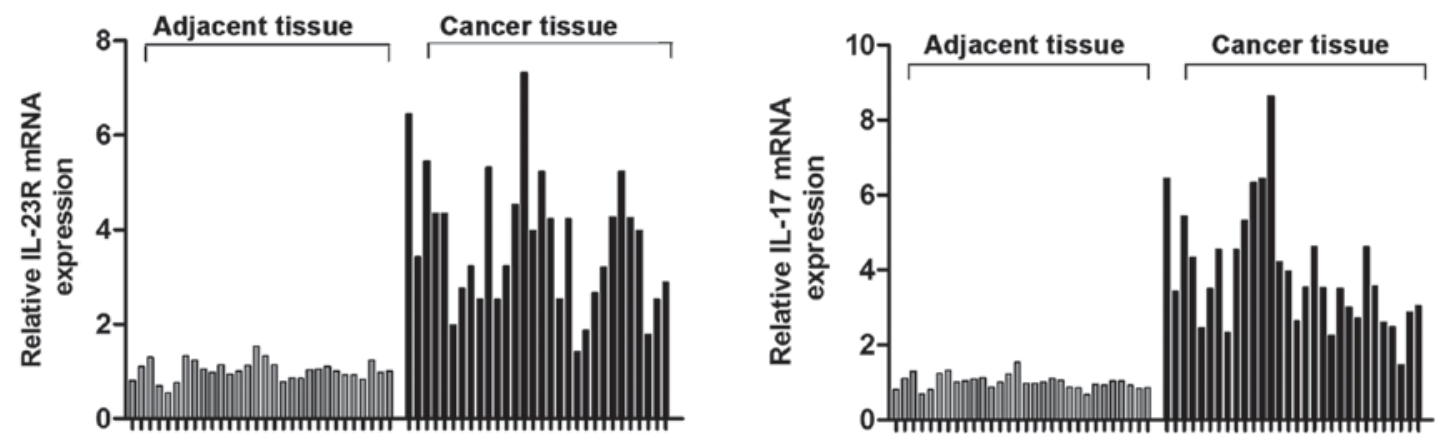

Figure 1. Expression levels of IL-23R and IL-17 in tumor tissue and adjacent healthy tissue of UBC patients. The levels of IL-23R and IL-17 mRNA in bladder cancer tissues were significantly higher than those in adjacent tissues. $\mathrm{P}<0.05$. IL-23R, interleukin-23 receptor; UBC, urinary bladder carcinoma.
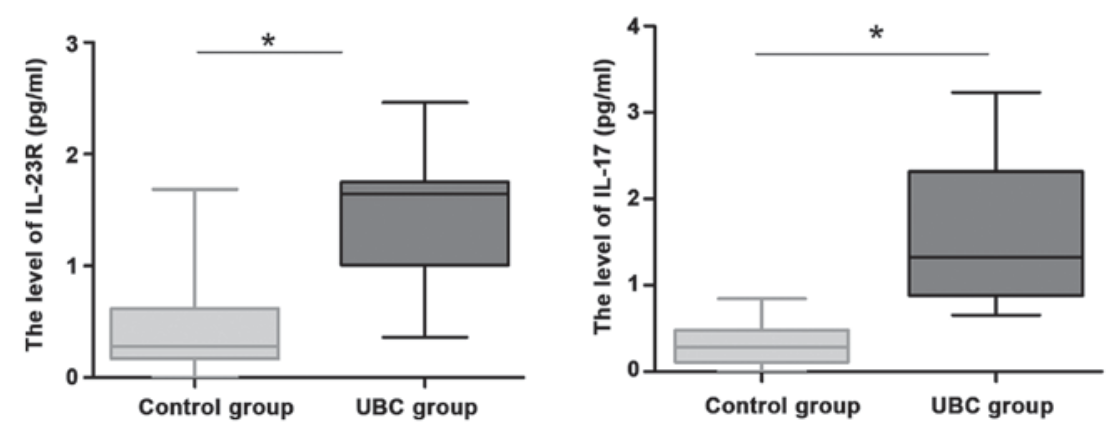

Figure 2. Serum levels of IL-23R and IL-17 protein in patients detected by ELISA. Serum IL-23R and IL-17 protein levels were measured by ELISA. The data were analyzed by independent sample t-test. The results suggested that the serum IL-23R and IL-17 protein levels in UBC patients were significantly higher than those in the control group. " $\mathrm{P}<0.05$, compared with control group. IL-23R, interleukin-23 receptor; UBC, urinary bladder carcinoma. 
Table II. Results of Cox hazard model analysis.

\begin{tabular}{lccccccc}
\hline Items & $\begin{array}{c}\text { Regression } \\
\text { coefficient (B) }\end{array}$ & SE & Wald test & Degrees of freedom & P-value & RR & 95.0\% confidence interval \\
\hline Sex & 1.073 & 0.263 & 1.342 & 1 & 0.302 & 0.872 & $0.543-1.378$ \\
Age & 0.873 & 0.211 & 0.892 & 1 & 0.236 & 1.237 & $0.915-1.528$ \\
Tumor size & 0.462 & 0.376 & 1.773 & 1 & 0.092 & 1.152 & $0.842-1.352$ \\
PG & 1.0832 & 0.353 & 2.421 & 2 & 0.517 & 1.037 & $0.884-1.379$ \\
CS & 0.542 & 0.426 & 8.342 & 1 & 0.044 & 2.603 & $1.741-2.905$ \\
LM & 0.782 & 0.284 & 10.261 & 1 & 0.009 & 2.154 & $2.035-2.553$ \\
IL-23R level & 0.882 & 0.118 & 7.231 & 1 & 0.011 & 3.021 & $2.648-3.527$ \\
IL-17 level & 1.245 & 0.205 & 11.528 & 1 & 0.006 & 2.604 & $2.184-3.017$ \\
\hline
\end{tabular}

SE, standard error; RR, relative risk; PG, pathological grade; CS, clinical stage; LM, lymphatic metastasis; IL-23R, interleukin-23 receptor.
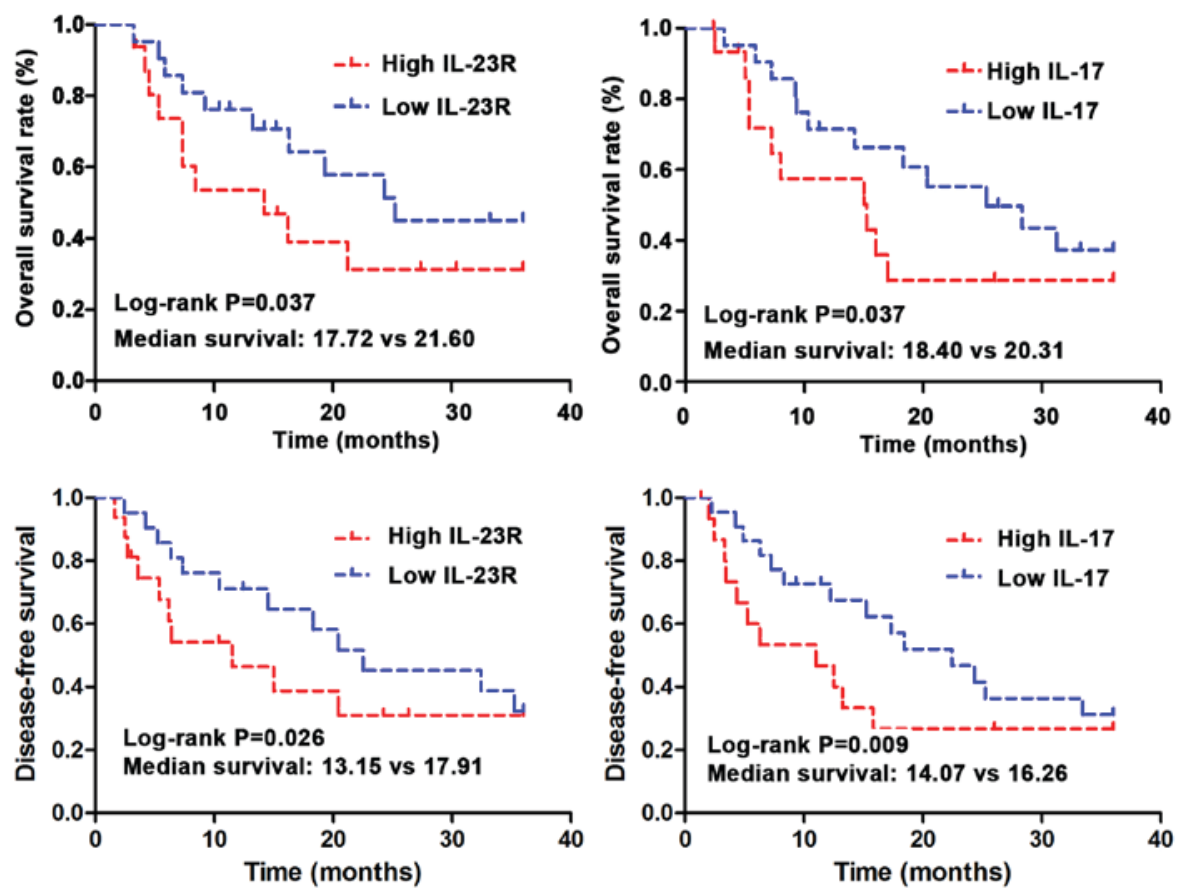

Figure 3. Relationship between IL-23R and IL-17 protein expression and prognosis of UBC patients. The results of Pearson correlation analysis suggested that there was a negative correlation between the expression of IL-23R and IL-17 protein in the serum of UBC patients. IL-23R, interleukin-23 receptor; UBC, urinary bladder carcinoma.

Correlation between IL-23R and IL-17 protein expression and prognosis of UBC patients. Kaplan-Meier method was used to investigate the correlations between expression of IL-23R and IL-17 and the overall survival (OS) time and disease-free survival (DFS). The data were analyzed using log-rank test. As shown in Fig. 3, OS and DFS is significantly shorter in IL-23R and IL-17 high expression group than those in low expression group $(\mathrm{P}<0.05)$. Median OS was 20.31 months in IL-17 low expression group, and 18.40 months in IL-17 high expression group (log-rank test, $\mathrm{P}=0.037$ ). Median $\mathrm{OS}$ was 21.60 months in IL-23R low expression group, and 17.72 months in IL-23R high expression group (log-rank test, $\mathrm{P}=0.037)$. Median DFS was 16.26 months in IL-17 low expression group, and 14.07 months in IL-17 high expression group (log-rank test, $\mathrm{P}=0.009$ ). Median DFS was 17.91 months in IL-23R low expression group, and 13.15 months in IL-23R high expression group (log-rank test, $\mathrm{P}=0.026$ ).

ROC curve to analyze the diagnostic values of $I L-23 R$ and $I L-17$ protein levels for UBC. ROC curve was applied to analyze the diagnostic values of IL-23R and IL-17 protein levels for UBC. As shown with ROC curve (Table III) serum IL-23R and IL-17 protein levels can be used to accurately and effectively diagnose UBC $(\mathrm{P}<0.05)$. Serum IL-23R and IL-17 protein levels can be applied in the clinical stage and the forecast of lymph node metastasis of UBC $(\mathrm{P}<0.05)$, and in the clinical stage, area under ROC curve of serum IL-17 protein level was larger than that of serum IL-23R protein level, so serum IL-17 protein level was more significantly significant in the clinical stage of UBC. However, area under 
Table III. Effect of IL-23R and IL-17 protein levels on parameters of clinical staging and lymph node prediction in UBC patients.

\begin{tabular}{llcccc}
\hline Items & Proteins & Area under ROC curve & Area standard error & P-value & 95\% confidence interval \\
\hline CS & IL-23R & 0.639 & 0.055 & 0.011 & $0.009-0.032$ \\
& IL-17 & 0.740 & 0.043 & 0.008 & $0.003-0.683$ \\
LM & IL-23R & 0.836 & 0.084 & 0.028 & $0.016-0.053$ \\
& IL-17 & 0.694 & 0.105 & 0.013 & $0.007-0.063$
\end{tabular}

IL-23R, interleukin-23 receptor; UBC, urinary bladder carcinoma; CS, clinical stage; LM, lymphatic node metastasis.

Table IV. Diagnostic efficiency of IL-23R combined with IL-17 for UBC.

\begin{tabular}{lcccc}
\hline $\begin{array}{l}\text { Detection } \\
\text { index }\end{array}$ & $\begin{array}{c}\text { Specificity } \\
(\%)\end{array}$ & $\begin{array}{c}\text { Sensitivity } \\
(\%)\end{array}$ & $\begin{array}{c}\text { Positive } \\
\text { predictive } \\
\text { value }\end{array}$ & $\begin{array}{c}\text { Negative } \\
\text { predictive } \\
\text { value }\end{array}$ \\
\hline IL-23R & 75.3 & 38.3 & 75.4 & 38.5 \\
IL-17 & 83.8 & 53.7 & 80.4 & 48.3 \\
IL-23R + IL-17 & $89.4^{\mathrm{a}, \mathrm{b}}$ & $62.5^{\mathrm{a}, \mathrm{b}}$ & 87.9 & 45.7 \\
\hline
\end{tabular}

IL-23R, interleukin-23 receptor; UBC, urinary bladder carcinoma. ${ }^{\mathrm{a}} \mathrm{P}<0.05$, compared with IL-23R; ${ }^{\mathrm{b}} \mathrm{P}<0.05$, compared with IL- 17 .

ROC curve of serum IL-23R protein level in the forecast of lymph node metastasis was larger than that of serum IL-17 protein level, so serum IL-23R protein level was more obviously significant in the forecast of lymph node metastasis of UBC.

Analysis of diagnostic efficiency of IL-23R combined with $I L-17$ for $U B C$. The diagnostic sensitivity and specificity of serum IL-23R + IL-17 for UBC patients were significantly higher than those of IL-23R or IL-17 alone (Table IV).

\section{Discussion}

Inflammation is considered to be an important factor in the progression of tumors. Studies have shown that proinflammatory cytokines can promote the proliferation of different tumor cells and tumor-related white blood cells, so as to play an important role in inhibiting tumor regeneration (16). But at the same time proinflammatory cytokines have also been proven to contribute to tumor growth and proliferation. For example, IL-1 and IL-6 can induce tumor cell proliferation and prolong tumor cell survival (17). IL-17 is mainly produced and secreted by activated CD4 T cells and CD8 T cells. In addition to proinflammatory reactions, IL-17 can also regulate the formation of tight junctions of cells (18). IL-17-positive cells have been observed in prostate and hepatocellular carcinoma. IL-17 plays a role in promoting tumor regeneration and increasing the invasive ability of tumors in cervical cancer (19). In addition, IL-17 is also highly expressed in ovarian cancer and colorectal cancer to play a role in promoting tumor angiogenesis (20). Bagheri et al reported that IL-17 had important functions in $\mathrm{T}$ cell-mediated angiogenesis (21).
Infiltration of proinflammatory cytokines is considered to be the growth promoter of UBC. Recently, IL-17 has been shown to increase the production of active metalloproteinase-9, so as to promote angiogenesis and tumor growth (22). Therefore, IL-17 may also have important functions in UBC.

IL-23 and IL-23R subunits make up a new complex of IL-12RB1 called IL-23R10. These two cytokines are mainly expressed by activated dendritic cells and phagocytic cells. IL-23R is mainly expressed in T cells, natural killer cells and natural killer T cells (23). Recently, expression of IL-23R was detected in macrophages and dendritic cells in human and mouse tumor tissues. Studies also found that IL-23 induced the expression of IL-17 and matrix metalloproteinase, while IL-23R-deficient mice showed reduced tumor growth. In addition, with the progress of tumor, the number of Th17 cells gradually increased, and levels of IL-23R and its complex also gradually increased (24).

Chronic inflammation plays pivotal roles in cancer and autoimmune diseases. We hypothesized that IL-17 and IL-23 may also play important roles in UBC. To verify this, RT-PCR and ELISA were used to detect the expression of IL-23R in tumor tissue and serum of patients with UBC. Results showed that levels of IL-23R and IL-17 mRNAs were higher in tumor tissue than in adjacent tissue. In addition, levels of IL-23R and IL-17 in serum of patients with UBC were also higher than those in normal control group. Correlation analysis suggested that IL-23R and IL-17 protein levels were correlated with clinical stage and lymphatic metastasis. Further Cox hazard model analysis showed that IL-23R and IL-17 may be independent factors for UBC. In addition, protein levels of IL-23R and IL-17 in serum of UBC patients can be used to effectively predict clinical stage and lymphatic metastasis of UBC. The sensitivity and specificity of combined diagnosis using both IL-23R and IL-17 were higher than those of diagnosis using IL-23R or IL-17 alone. In conclusion, we found that IL-23R and IL-17 were upregulated in UBC tumor tissue, and the increased expression levels were associated with poor prognosis. IL-23R and IL-17 may serve as potential diagnostic and prognostic indicators for UBC.

\section{Acknowledgements}

Not applicable.

\section{Funding}

No funding was received. 


\section{Availability of data and materials}

The datasets used and/or analyzed during the present study are available from the corresponding author on reasonable request.

\section{Authors' contributions}

$\mathrm{JL}$ conceived and designed the study. JL and LW were responsible for the collection and analysis of the patient data. TW and JW interpreted the data and drafted the manuscript. $\mathrm{JL}$ and $\mathrm{JW}$ revised the manuscript critically for important intellectual content. All authors read and approved the final study.

\section{Ethics approval and consent to participate}

The study was approved by the Ethics Committee of Zhengzhou Central Hospital Affiliated to Zhengzhou University, (Zhengzhou, China). Signed informed consents were obtained from the patients or the guardians.

\section{Patient consent for publication}

Not applicable.

\section{Competing interests}

The authors declare that they have no competing interests.

\section{References}

1. Pernot S, Terme M, Voron T, Colussi O, Marcheteau E, Tartour E and Taieb J: Colorectal cancer and immunity: What we know and perspectives. World J Gastroenterol 20: 3738-3750, 2014.

2. Ikemoto T, Shimada M, Ishikawa D, Teraoku H, Yoshikawa M, Yamada S, Takasu C, Saito Y, Morine Y and Imura S: The clinical impact of $\mathrm{CD}^{+} \mathrm{CD}^{+} 9 \mathrm{~b}^{+}$regulatory $\mathrm{T}$ cells addition to $\mathrm{FOXp3}^{+}$regulatory $\mathrm{T}$ cells in cancer patients' immunity. $\mathrm{J}$ Am Coll Surg 221: e22, 2015.

3. Zhong Z, Sanchez-Lopez E and Karin M: Autophagy, inflammation, and immunity: A troika governing cancer and its treatment. Cell 166: 288-298, 2016.

4. Chang WJ, Du Y, Zhao X, Ma LY and Cao GW: Inflammationrelated factors predicting prognosis of gastric cancer. World J Gastroenterol 20: 4586-4596, 2014.

5. Shalapour S and Karin M: Immunity, inflammation, and cancer: An eternal fight between good and evil. J Clin Invest 125: $3347-3355,2015$

6. Tran E, Turcotte S, Gros A, Robbins PF, Lu YC, Dudley ME, Wunderlich JR, Somerville RP, Hogan K, Hinrichs CS, et al Cancer immunotherapy based on mutation-specific $\mathrm{CD}^{+}{ }^{+} \mathrm{T}$ cells in a patient with epithelial cancer. Science 344: 641-645, 2014.

7. Chen DS and Mellman I: Oncology meets immunology: The cancer-immunity cycle. Immunity 39: 1-10, 2013.

8. Yan J, Smyth MJ and Teng MWL: Interleukin (IL)-12 and IL-23 and their conflicting roles in cancer. Cold Spring Harb Perspect Biol: Jul 17, 2017 (Epub ahead of print).
9. Stanilov N, Miteva L, Deliysky T, Jovchev J and Stanilova S: Advanced colorectal cancer is associated with enhanced IL-23 and IL-10 serum levels. Lab Med 41: 159-163, 2010.

10. Coffelt SB, Kersten K, Doornebal CW, Weiden J, Vrijland K, Hau CS, Verstegen NJM, Ciampricotti M, Hawinkels LJAC, Jonkers $\mathrm{J}$, et al: IL-17-producing $\gamma \delta \mathrm{T}$ cells and neutrophils conspire to promote breast cancer metastasis. Nature 522: 345-348, 2015.

11. Lin Q, Xue L, Tian T, Zhang B, Guo L, Lin G, Chen Z, Fan K and Gu X: Prognostic value of serum IL-17 and VEGF levels in small cell lung cancer. Int J Biol Markers 30: e359-e363, 2015.

12. Fabre J, Giustiniani J, Garbar C, Antonicelli F, Merrouche Y, Bensussan A, Bagot M and Al-Dacak R: Targeting the tumor microenvironment: The protumor effects of IL-17 related to cancer type. Int J Mol Sci 17: E1433, 2016.

13. Iwakura $\mathrm{Y}$ and Ishigame $\mathrm{H}$ : The IL-23/IL-17 axis in inflammation. J Clin Invest 116: 1218-1222, 2006.

14. Liang SC, Tan XY, Luxenberg DP, Karim R, Dunussi-Joannopoulos K, Collins M and Fouser LA: Interleukin (IL)-22 and IL-17 are coexpressed by Th17 cells and cooperatively enhance expression of antimicrobial peptides. J Exp Med 203: 2271-2279, 2006.

15. Livak KJ and Schmittgen TD: Analysis of relative gene expression data using real-time quantitative PCR and the 2(-Delta Delta C(T)) method. Methods 25: 402-408, 2001.

16. Sica A, Allavena P and Mantovani A: Cancer related inflammation: The macrophage connection. Cancer Lett 267: 204-215, 2008.

17. Grivennikov S, Karin E, Terzic J, Mucida D, Yu GY, Vallabhapurapu S, Scheller J, Rose-John S, Cheroutre H, Eckmann L, et al: IL-6 and Stat 3 are required for survival of intestinal epithelial cells and development of colitis-associated cancer. Cancer Cell 15: 103-113, 2009.

18. Yamaguchi Y, Fujio K, Shoda H, Okamoto A, Tsuno NH, Takahashi K and Yamamoto K: IL-17B and IL-17C are associated with TNF-alpha production and contribute to the exacerbation of inflammatory arthritis. J Immunol 179: 7128-7136, 2007.

19. Punt S, Fleuren GJ, Kritikou E, Lubberts E, Trimbos JB, Jordanova ES and Gorter A: Angels and demons: Th17 cells represent a beneficial response, while neutrophil IL-17 is associated with poor prognosis in squamous cervical cancer. OncoImmunology 4: e984539, 2015.

20. Straus DS: TNF $\alpha$ and IL-17 cooperatively stimulate glucose metabolism and growth factor production in human colorectal cancer cells. Mol Cancer 12: 78, 2013.

21. Bagheri N, Azadegan-Dehkordi F, Shirzad H, Rafieian-Kopaei M, Rahimian $\mathrm{G}$ and Razavi A: The biological functions of IL-17 in different clinical expressions of Helicobacter pylori-infection. Microb Pathog 81: 33-38, 2015.

22. $\mathrm{Li} \mathrm{L}$ and Boussiotis VA: The role of IL-17-producing Foxp $3^{+} \mathrm{CD}^{+}$ $\mathrm{T}$ cells in inflammatory bowel disease and colon cancer. Clin Immunol 148: 246-253, 2013.

23. Helbling M, Lukesch A, Haimovici A, Karamitopoulou E, Berger MD, Hädrich M, Mallaev M, Schnüriger B, Koelzer VH, Dawson H, et al: Investigation of IL-23 (p19, p40) and IL-23R identifies nuclear expression of IL-23 p19 as a favorable prognostic factor in colorectal cancer: A retrospective multicenter study of 675 patients. Oncotarget 5: 4671-4682, 2014.

24. Chen G, Liang Y, Guan X, Chen H, Liu Q, Lin B, Chen C, Huang M, Chen J, Wu W, et al: Circulating low IL-23: IL-35 cytokine ratio promotes progression associated with poor prognosisin breast cancer. Am J Transl Res 8: 2255-2264, 2016.

(†) $\Theta$ This work is licensed under a Creative Commons Attribution-NonCommercial-NoDerivatives 4.0 International (CC BY-NC-ND 4.0) License. 